\title{
Depoimento Especial de Crianças: Um Lugar Entre Proteção e Responsabilização?
}

Special Testimonies From Children: Somewhere Between Protection and Responsibility?

Testimonio Especial de Niños: $\dot{z}$ Un Lugar entre Protección y Responsabilización?

\section{José César Coimbra}

Universidade Federal do Estado do Rio de Janeiro

http://dx.doi.org/10.1590/1982-3703000732013

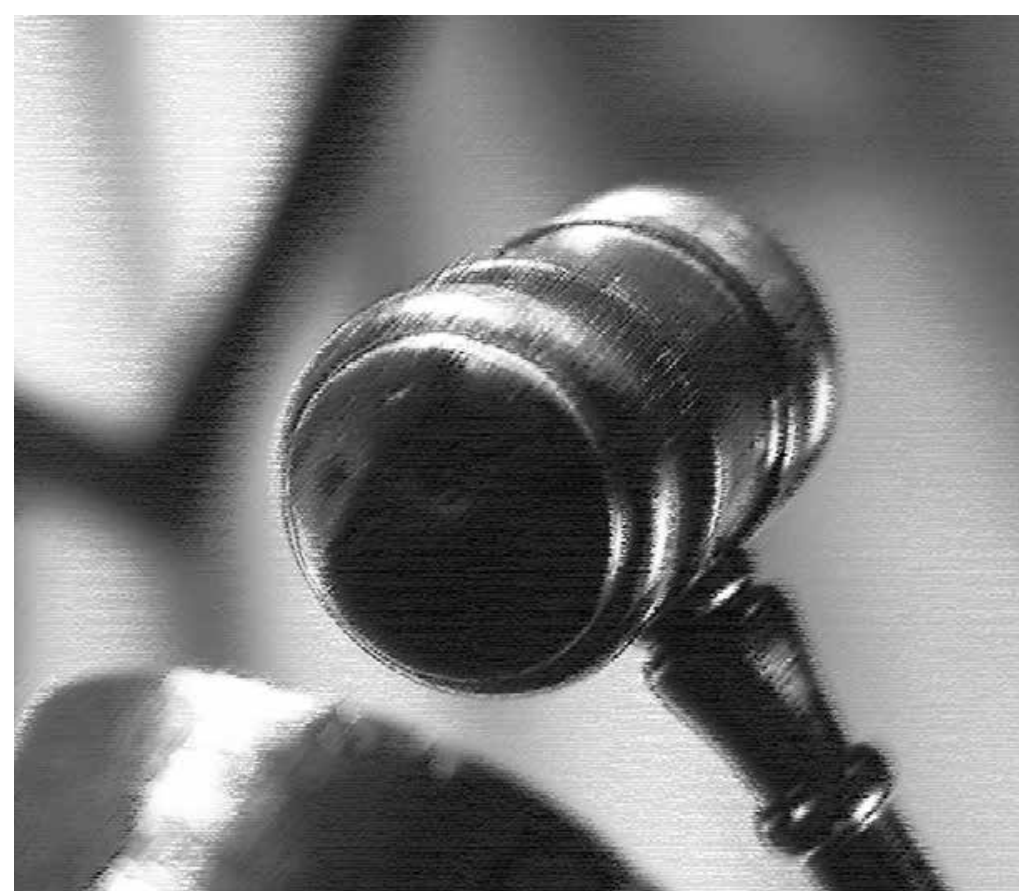


A realidade é a sombra da palavra.

Bruno Schulz (2012)

Resumo: Este trabalho aborda o tema do depoimento judicial de crianças. Com base em pesquisa documental e bibliográfica, comenta-se a experiência canadense nesse empreendimento. Destaca-se o que nela se diferencia dos procedimentos em discussão no Brasil. Constata-se que não existe uniformidade entre a prática canadense e a nossa, em particular quanto à figura do intermediário. Observa-se que, sob a definição de depoimento especial, um conjunto de práticas diferentes entre si podem ser invocadas e que o papel de intermediário é previsto em diretrizes e práticas internacionais. Verifica-se que a prática canadense encontrase alinhada às diretrizes da ONU sobre a prática do depoimento especial. Esse alinhamento confere a ela legitimidade calcada em princípios fundamentais dos Direitos Humanos. Aponta-se, ainda, a possibilidade de uma análise desse campo que inclua as vicissitudes da memória e do testemunho, tais como estudadas por Agamben e Seligmann-Silva. Conclui-se que há certo grau de opacidade no testemunho não passível de dissolução total em procedimentos narrativos.

Palavras-chave: Memória Subjetiva. Memória social. Direitos Humanos. Justiça.

Abstract: This paper addresses the issue of judicial testimony from children. Based on research documents and literature, we comment the Canadian experience in this issue. We highlight what is different from it relating to the procedures under discussion in Brazil. It appears that there is no uniformity between the Canadian practice and ours, in particular with the figure of the intermediary. We observed that under the definition of special testimony, a set of different practices may be invoked and that the role of intermediary is foreseen in international guidelines and practices. Canadian practice is aligned with UN guidelines on the practice of special testimony. This alignment gives it legitimacy grounded in fundamental Human Rights principles. Furthermore, we indicate the possibility of an analysis of this field that includes the vicissitudes of memory and of testimony, such as studied by Agamben and Seligmann-Silva. We concluded that there is some degree of opacity in testimony not liable to the complete dissolution of narrative procedures.

Keywords: Subjective memory. Social memory. Human rights. Justice.

Resumen: Este trabajo aborda el tema del testimonio judicial de niños. Con base en investigación documental y bibliográfica, se comenta la experiencia canadiense en ese emprendimiento. Se destaca lo que en ella se diferencia de los procedimientos en discusión en Brasil. Se constata que no existe uniformidad entre la práctica canadiense y la nuestra, especialmente en cuanto a la figura del intermediario. Se observa que, bajo la definición de testimonio especial, un conjunto de prácticas diferentes entre sí se pueden invocar y que la función del intermediario está prevista en directrices y prácticas internacionales. Se verifica que la práctica canadiense se encuentra alineada a las directrices de la ONU acerca de la práctica del testimonio especial. Esa alineación le atribuye legitimidad basada en principios fundamentales de los Derechos Humanos. Asimismo, se señala la posibilidad de un análisis de ese campo que incluya las vicisitudes de la memoria y del testimonio, tales como estudiadas por Agamben y Seligmann Silva. Se concluye que hay cierto grado de opacidad en el testimonio no pasible de disolución total en procedimientos narrativos.

Palabras clave: Memoria subjetiva. Memoria social. Derechos humanos. Justicia.

A apresentação do Projeto de Lei (PL) no 4.126 (2004), que originalmente acrescentaria artigo no Código de Processo Penal (CPP) para determinar regras na realização de laudo pericial e psicossocial nos crimes contra a liberdade sexual de criança ou adolescente, foi um dos marcos do mal-estar e da incompreensão que ainda perduram. A partir dos substitutivos que caracterizaram o projeto como associado ao "depoimento sem dano" (Brito, 2012), estabeleceram-se duas forças contrárias: uma, de forma geral, reconhecida nos profissionais do direito, mostra-se favorável à implementação imediata desse procedimento, conforme manifestação do Conselho Nacional de Justiça (CNJ)
(Recomendação 33, 2010). Outra, que, grosso modo, poderia ser representada no Conselho Federal de Psicologia (CFP), sobretudo a partir de sua Resolução no 10 (2010), opõe-se a esse procedimento (Senado Federal, 2008). Os argumentos dessas duas posições já foram sistematizados por Brito e Parente (2012), tendo sido a sucessão dos projetos de lei, até o substitutivo ao PL no 156/09, analisada por Brito (2012). A despeito da conclusão da audiência pública de que a proposta ainda deveria ser debatida, é certo que a prática espalha-se pelo Brasil (Brito, 2012).

O primeiro aspecto que abordaremos neste trabalho, que tem por base levantamento 
documental e bibliográfico, diz respeito aos equívocos que existem quando se toma a experiência de depoimento especial de crianças e adolescentes como unívoca. Em realidade, trata-se de práticas diversas, inclusive quanto ao que ocorre no Brasil (Brito, 2012). Nossa proposta é a de estudar alguns aspectos do modelo canadense de depoimento especial, particularmente daquele realizado na província de Ontário, pelo Centre for Children \& Families in the Justice System. Subsidiariamente, serão feitos comentários com base em outras referências internacionais do mesmo gênero.

Em segundo lugar, analisaremos de que forma pressupostos implícitos na prática da tomada de depoimento de crianças e adolescentes implicam a relação entre testemunho e memória. Essa relação revela aporias inerentes a essas concepções, tais como destacadas por Agamben (2008) e Seligmann-Silva (2009).

\section{Os procedimentos: uma introdução}

Deve ser frisado que as querelas em torno desse tipo de procedimento não são exclusivas do Brasil, como se nota no balanço de dez anos dessa prática na África do Sul (Jonker \& Swanzen, 2007). Discussões em torno desse tema existem e possuem vários focos, tais como: dificuldades inerentes ao diálogo interdisciplinar envolvendo o sistema judicial; falta de consenso em torno de questões como influência da sugestão no testemunho e falsas memórias; especulações sobre eficácia do sistema penal versus garantia de direitos e práticas de justiça restaurativa; lugar e grau de autonomia do intermediário no procedimento (Jonker \& Swanzen, 2007; Motzkau, 2005).

Em síntese, esse procedimento, tal como realizado ou proposto no Brasil (Brito,
2012), consiste no uso de intermediários (psicólogos, por exemplo), que, em tese, teriam familiaridade em sua formação (ou teriam recebido treinamento específico para intervir) na lida com crianças e adolescentes. Em geral, durante as audiências (ou previamente a elas), esses profissionais recebem as indagações relacionadas ao processo judicial e as repassam à criança. Sala de audiência e sala de tomada do depoimento especial são distintas, havendo interligação entre elas (por meio de circuito fechado de TV ou sala de espelhos) de forma a haver transmissão de som e imagem em tempo real entre uma e outra. Ao final, tudo é registrado em mídia que passa a compor o processo judicial.

Diferentemente do que se poderia imaginar, a prática de depoimento especial não necessariamente implica diminuição significativa do número de vezes que a criança narra sua versão do ocorrido, como constata lucksch (2012) com relação à experiência francesa. Ou seja, não decorre do procedimento que automaticamente a criança deponha menos vezes. Isso dependerá de arranjos que envolvem coordenação entre organizações distintas e de ajustes internos a essas mesmas organizações, tais como o poder judiciário, a polícia, a saúde e a assistência social.

Esses aspectos constituem-se em linhas importantes de análise para avaliar as práticas correntes. Trata-se, em síntese, de pergunta sobre como o depoimento especial (ou a produção antecipada de prova) efetivamente será acolhido pelos diversos segmentos que são convocados para o atendimento de cada caso concreto, culminando na efetividade ou não do procedimento. Efetividade que deve ser entendida tanto no aspecto da proteção (da criança ou do adolescente) como no da responsabilização (daquele que terá sido identificado como autor da violência contra a criança ou o adolescente). 
Um ponto que não nos deve passar despercebido é que o Projeto de Lei $n^{\circ}$

4.126 (2004) originalmente dizia respeito ao tema de elaboração de laudos e pareceres psicossociais nos crimes contra a liberdade sexual de crianças e adolescentes (Brito, 2012).
Procedimentos especiais de tomada de depoimento de crianças em processos judiciais não são algo novo. Trata-se de experiência amplamente disseminada no mundo, embora não se possa deduzir daí que haja similitude integral entre os diversos exemplos (Alvarez, 2012; Santos \& Gonçalves, 2008) ou mesmo que as críticas a esse tipo de prática sejam inexistentes (Alvarez, 2012; Jonker \& Swanzen, 2007; Nascimento, 2012). Do mesmo modo, verifica-se que a avaliação do que seja sucesso ou insucesso desse procedimento muda de modo substancial conforme o país (Alvarez, 2012; New Zealand's Criminal Justice System, 2012).

Nesse sentido, sabe-se que em muitos lugares a etapa relativa à gravação de depoimento é apenas parte de uma série que concorre para que, de fato, proteção e responsabilização possam ser efetivas (Alvarez, 2012; Ministry of Justice, 2011; New Zealand's Criminal Justice System, 2012; Santos \& Gonçalves, 2008). Isto é, uma etapa apenas, não sendo sempre o momento mais importante do procedimento, como se depreende da prática canadense, da inglesa e das diretrizes da Organização das Nações Unidas (ONU) sobre o tema (Cunningham, 2011; Cunningham, 2011a; Cunningham \& Hurley, 2007; 2007a; Cunningham \& Stevens, 2011; Justice Education Society, 2012; Ministry of Justice, 2011; United Nations Economic and Social Council, 2005; United Nations Office on Drugs and Crime, 2009).

A utilização do depoimento especial tem, em síntese, quatro argumentos: i) a ineficácia do sistema criminal; ii) o suposto trauma ou dano causado à criança pela repetição incessante de sua narrativa sobre o episódio de violência ou pela inabilidade de se proceder à sua inquirição, isto é, tentativa de se evitar a vitimização secundária; iii) a garantia da melhor correspondência possível entre a lembrança da vítima e o fato ocorrido, de forma a minorar lapsos e retificações inerentes ao funcionamento da memória; iv) aprimoramento dos mecanismos de proteção e responsabilização.

Ao quadro acima deve ser adicionado que, somente na fase judicial, em média, a criança seria ouvida cerca de sete vezes no Brasil (D'Agostino, 2012). Isso pode ser traduzido em processos judiciais que se estendem por anos, envolvendo segmentos diferentes da justiça, como a infância e juventude e a criminal, primeira e segunda instâncias.

\section{O depoimento especial e o seu contexto}

Um ponto que não nos deve passar despercebido é que o Projeto de Lei no 4.126 (2004) originalmente dizia respeito ao tema de elaboração de laudos e pareceres psicossociais nos crimes contra a liberdade sexual de crianças e adolescentes (Brito, 2012). Sobre esse item empiricamente notamos que mesmo nos casos não relacionados à violência sexual, embora sem dúvida de modo mais reiterado nesses, a demanda do sistema judicial por laudos psicossociais sucessivos é recorrente, envolvendo profissionais diversos. Quais seriam os motivos dessa recorrência? $\mathrm{O}$ que se demanda às equipes técnicas seria passível de atendimento? E, por outro lado, o que nosso trabalho tem oferecido ao sistema judicial no que se refere aos casos de suspeitas de violência sexual contra crianças e adolescentes?

Essas indagações conduzem-nos à pergunta que deve ser respondida aqui: qual o lugar para o intermediário no procedimento de depoimento especial? Em nenhuma fonte consultada sobre as experiências no exterior encontramos textualmente a afirmação de que algum tipo de profissional seria inábil per se para a tomada de depoimento de crianças. Policiais, por exemplo, são citados com alguma 
recorrência (Davies \& Westcott, 1999; Santos \& Gonçalves, 2008; United Nations Office on Drugs and Crime, 2009). A despeito disso, há argumentos sobre a preferência por certos profissionais para esse empreendimento, pelo fato de conhecerem aspectos da infância, do desenvolvimento humano ou da linguagem. Todavia, isso sempre de modo secundário à discussão sobre a eficácia dos procedimentos, à possibilidade de treinamento e capacitação dos ali envolvidos e à atenção necessária à criança e ao adolescente antes, durante e depois do depoimento (New Zealand's Criminal Justice System, 2012; United Nations Office on Drugs and Crime, 2009).

Em tese o que se busca é um conjunto de conhecimentos, habilidades e competências que poderá colaborar na realização do depoimento. O grau de liberdade para o intermediário não reproduzir literalmente as questões recebidas, ou reproduzi-las parcialmente, varia de modo significativo na experiência internacional (Brito, 2012; Jonker \& Swanzen, 2007; Santos \& Gonçalves, 2008).

Sobre os papéis a serem assumidos nos procedimentos, há referências que sugerem a importância capital tanto do promotor de justiça como do juiz, na relação com a testemunha, sem se cogitar preferencialmente a atuação de intermediários (Convenção sobre os direitos da criança, 1989; Court \& Tribunal Services, 2013; Cunningham \& Hurley, 2007; 2007a; United Nations Economic and Social Council, 2005; United Nations Office on Drugs and Crime, 2009).

Devemos mencionar, no entanto, que nas orientações do United Nations Economic and Social Council - Ecosoc (2005) e do United Nations Office on Drugs and Crime - UNODC (2009) o papel de intermediário é previsto, sem que se trate de figura central para o procedimento. Em vários países o intermediário terá um papel a cumprir diante de alguns casos, como na Inglaterra. Ali, ele intervém junto às testemunhas consideradas vulneráveis. Todos os menores de 18 anos encontram-se nessa categoria (Ministry of Justice, 2011).

No Canadá, onde não há a figura do intermediário, alguns detalhes convergem para a eficácia e efetividade do procedimento: i) treinamento e coordenação dos agentes envolvidos nos casos de suspeita de violência sexual contra criança, dentro e fora do sistema judicial; ii) flexibilidade quanto ao modo de tomada de depoimento; iii) arquitetura e metodologia adotadas e iv) material de divulgação sobre como ocorre a participação de crianças e adolescentes em processos judiciais (Cunningham, 2011; Cunningham, 2011a; Cunningham \& Hurley, 2007; 2007a; 2007b; Justice Education Society, 2012). É essa flexibilidade do procedimento da experiência canadense, com foco na atenção das necessidades da criança e do adolescente, alinhada às orientações do Ecosoc e UNODC, que nos faz destacá-la dentre as demais práticas internacionais.

Ao mirarmos a experiência canadense, observamos que a ampliação da eficácia da garantia de direitos relacionada a casos de suspeita de violência sexual contra crianças e adolescentes envolve, muitas vezes, mudanças de leis e de práticas judiciárias, além do próprio modo como a sociedade posiciona-se frente a esse tema. No Canadá, os últimos vinte anos foram de transformações acentuadas em todas essas dimensões até se chegar à configuração atual (Cunningham, 2011a). Essas transformações apenas de modo secundário estão ligadas ao avanço técnico em sentido estrito, conforme Cunningham (2011a) nos recorda: "quando atuamos com crianças o mais importante não é o material ou equipamento tecnológico que se tem, e sim, o componente humano - as pessoas que trabalham com elas" (p. 164). 
Um ponto que alinha a experiência canadense com as diretrizes da ONU, presente também em algumas práticas no Brasil, refere-se à importância da "figura de confiança" ou "pessoa de confiança" ou, ainda, "pessoa de suporte" no depoimento especial (United Nations Economic and Social Council, 2005; United Nations Office on Drugs and Crime, 2009).No Canadá, essa função tem papel de destaque e é considerada como fator de sucesso na proteção da criança e na responsabilização dos autores de violência, sendo utilizada em cerca de $90 \%$ dos testemunhos dos menores de 14 anos nesse país (Cunningham, 2011a; Cunningham \& Hurley, 2007; 2007b; Northcott, 2011). No Reino Unido, esse recurso também é previsto (Ministry of Justice, 2011).

Tal figura não necessariamente seria um profissional (ainda que possa sê-lo, conforme Cunningham, 2011a), mas alguém que exerça a função de suporte emocional para o depoente e que receba o treinamento e/ou as informações cabíveis quanto ao desempenho dessa função, se for preciso. Não se trata de intermediário, pois à pessoa de suporte não é permitido falar ou interferir de qualquer modo no depoimento.

A pessoa de confiança ou de suporte não necessariamente suprime a necessidade de intervenções sobre a criança. Essas teriam o objetivo de prepará-la para o depoimento, bem como de verificar sua possibilidade de passar por essa experiência. No Canadá, isso está associado às sessões de preparação e às atribuições diversas dos serviços de apoio às vítimas. Dentre essas atribuições podem ser citados os agenciamentos para obtenção de informações de outros órgãos e os atendimentos que se fizerem oportunos à criança ou à sua família antes ou depois das audiências (Cunningham \& Hurley, 2007b).

As sessões de preparação, em síntese, têm por objetivo: i) familiarizar o depoente (e sua família) aos ritos e personagens próprios ao depoimento; ii) esclarecer o significado do depoimento e quaisquer dúvidas existentes; iii) identificar necessidades da criança/do adolescente e proceder aos encaminhamentos cabíveis; iv) verificar as condições da criança/ do adolescente em realizar o depoimento. Objetiva-se, assim, que o devido processo legal fique efetivamente assegurado para todos os envolvidos, do mesmo modo como a atenção às necessidades das crianças e adolescentes atendidos.

A questão principal, aqui, seria: a criança está preparada para depor? De que modo fortalecê-la para que isso possa ocorrer? As condições de atenção às necessidades dela antes, durante e após o julgamento estão asseguradas? Em todas essas questões, a "pessoa de confiança" pode desempenhar papel relevante, bem como os serviços de apoio às vítimas. No Reino Unido, a função do intermediário é a de assistir a testemunha vulnerável explicando a ela as questões que the são encaminhadas, tanto quanto igualmente explicar aos atores jurídicos as respostas dadas pela testemunha. A pessoa de suporte, como indicado igualmente na prática canadense, tem por objetivo fornecer amparo emocional à testemunha (Ministry of Justice, 2011).

A localização da criança durante o depoimento no Canadá ocorre segundo uma gama variada de possibilidades: na própria sala de audiências, mas em ala própria para essa finalidade, separada por painéis; em sala especial; em outro lugar que disponha dos recursos técnicos necessários para a transmissão de dados (Cunningham \& Hurley, 2007; 2007a; 2007b; Cunningham \& Stevens, 2011; Justice Education Society, 2012). Documentos diversos ilustram os arranjos arquitetônicos necessários para atender às possibilidades de depoimento especial no Canadá (Cunningham \& Hurley, 2007b; Justice Education Society, 2012). 
O argumento de que casos de violência sexual não deixam marcas materiais deveria, por si mesmo, significar que exatamente nesses casos tornam-se necessários modos aprimorados de investigação e não o contrário.
Existe ampla margem de possibilidades também quanto à localização do promotor de justiça e do advogado de defesa na experiência canadense durante a tomada de depoimento da criança (Justice Education Society, 2012). Ainda quanto à prática canadense, o juiz pode entender não ser a melhor alternativa o depoimento da criança/ adolescente. Para tanto, haveria modos outros de ouvir o seu testemunho, como o hearsay testimony, no qual o discurso do depoente é reproduzido ao juiz por um adulto (Cunningham \& Hurley, 2007). Esse recurso, no entanto, é evitado. No limite, o juiz pode também decidir não ouvir a criança ou o adolescente.

Cabe registrar que uma personagem similar à "pessoa de confiança" aparece com destaque em Fürniss quanto à relevância que possui na atenção a crianças e adolescentes vítimas de violência sexual (Coimbra, 2001; Fürniss, 1993). Essa figura é aquela a quem a criança dirige primeiramente a narrativa sobre o fato ocorrido, aquela que é escolhida pela criança para ser depositária inicial de sua narrativa. Trata-se de ator capital no trabalho a ser realizado pela equipe técnica interprofissional responsável pelo caso, segundo esse autor.

\section{O procedimento e o Sistema de Garantia de Direitos: dissonâncias?}

Conforme a Resolução Conanda no 113 (2006) entende-se o Sistema de Garantia de Direitos (SGD) como uma ampla articulação e integração das instâncias públicas governamentais e não governamentais em prol da garantia de direitos de crianças e adolescentes. Depreende-se daí que para a efetividade dos regimes de proteção e responsabilização é preciso que se reconheçam os limites que cercam a intervenção de cada um dos agentes envolvidos e os efeitos de cada ação sobre os demais, daí a postulação de um sistema (Ramos, 2010).

Não é por outro motivo que o rol de sugestões e recomendações oriundas do I Encontro Nacional de Experiências de Tomada de Depoimento realizado em Brasília, em 2011, ultrapassa o poder judiciário (Childhood, 2011). Dentre os diversos itens mencionados nesse Encontro, temos: "formar juízes, promotores de justiça e defensores públicos para participar, quando necessário, da coleta do depoimento especial". Tão importante quanto o item anterior, segundo as recomendações e sugestões do Encontro, é também "formar juízes para proceder à entrevista de crianças e adolescentes vitimizados que manifestem interesse em serem ouvidas [sic] pelo próprio magistrado" (Childhood, 2011).

A despeito de todas as dificuldades imagináveis para a realização de investigação policial no contexto de violência sexual contra crianças, não se pode deixar de investir nessa forma de atuação (United Nations Office on Drugs and Crime, 2009). O argumento de que casos de violência sexual não deixam marcas materiais deveria, por si mesmo, significar que exatamente nesses casos tornam-se necessários modos aprimorados de investigação e não o contrário. Esses modos aprimorados podem ser observados em algumas unidades especializadas, tais como: Sexual Offences and Child Abuse Investigation Teams, de Vitória, Austrália, e The Sexual Assault \& Child Abuse Section, de Ottawa, Canadá. De outra forma, como o sistema judicial poderá proceder efetivamente à garantia e à responsabilização necessárias em cada caso concreto?

O Brasil, em geral, possui taxas extremamente baixas de resolução de 
crimes, independentemente deles estarem ligados à integridade sexual das vítimas, conforme aponta o Conselho Nacional do Ministério Público (2012). Dessa forma, os argumentos de que os processos judiciais referentes à violência sexual contra crianças possuem baixa taxa de condenação deveriam ser compreendidos também segundo essa realidade.

Essa perspectiva sistêmica sobre a análise do procedimento é inescapável. Do não funcionamento da rede decorre a falta de efetividade das medidas protetivas e de responsabilização. Não por acaso, em seminário realizado no Ministério Público do Estado do Rio de Janeiro - MPRJ (2012), a promotora do Ministério Público do Rio Grande do Sul (MPRS), Flávia Malmann, ao relatar a experiência de Porto Alegre, salientou, ainda que de modo cauteloso, maior eficácia no fluxo de atendimento de crianças supostamente vítimas de violência depois da implantação do procedimento de depoimento especial naquela cidade. Ou seja, tentou-se ali estabelecer o papel e a função de cada agente da rede de atendimento de modo a não haver repetição de procedimentos, sendo o depoimento de responsabilidade exclusiva do juiz, com o auxílio do intermediário.

A cautela a que nos referimos diz respeito à manifestação da promotora de que esse equilíbrio tem instabilidades relativas a mudanças de profissionais na rede mencionada, bem como do entendimento que cada um dos envolvidos possui de sua inserção nesse sistema. Ou seja, não se trata de algo que uma vez acordado permaneceria funcional para sempre. Esse sistema necessita de ajustes periódicos e pressupõe, por consequência, algum grau de proximidade e coordenação entre os atores envolvidos.

\section{O procedimento e suas referências normativas}

A diretriz, sem dúvida, da inserção de cada ator no SGD e, por conseguinte, no depoimento especial de crianças e adolescentes no que se refere ao sistema judicial, deveria ser a prevista na Convenção Internacional de Direitos da Criança (1989). Em seu artigo 12, podemos ler que:

Os Estados Partes garantem à criança com capacidade de discernimento o direito de exprimir livremente a sua opinião sobre as questões que lhe respeitem, sendo devidamente tomadas em consideração as opiniões da criança, de acordo com a sua idade e maturidade.

Para este fim, é assegurada à criança a oportunidade de ser ouvida nos processos judiciais e administrativos que Ihe respeitem, seja diretamente, seja através de representante ou de organismo adequado, segundo as modalidades previstas pelas regras de processo da legislação nacional.

Observa-se, na citação acima, que não há uma oposição a que a criança seja ouvida diretamente. Quanto a isso, cabe ainda mencionar que no Estatuto da Criança e do Adolescente - ECA (Lei no 8.069, de 1990), as referências à oitiva de criança e adolescente estão associadas, basicamente, a três circunstâncias: perda ou suspensão do poder familiar (art. 161); colocação em família substituta (art. 168) e ato infracional, com relação ao qual especificamente é mencionada a possibilidade de que a oitiva do adolescente possa ser acompanhada de opinião de profissional qualificado (art. 186). As medidas de proteção também implicam a oitiva de criança ou adolescente, podendo haver ou não presença de adulto (art. 100).

A análise do Código de Processo de Penal CPP (Decreto-Lei no 3.689, de 1941) revela a importância da prova testemunhal, uma vez que ela supre a inexistência do exame 
de corpo de delito (art. 167), bem como a falta de exame complementar (art. 168). Ali, ainda, está definido que a testemunha assume a obrigação de falar a verdade em audiência (art. 203), derivando daí seu valor. Todavia, os menores de 14 anos não assumem esse compromisso (art. 208). Ou seja, formalmente não há o compromisso de menores de 14 anos falarem a verdade em juízo.

Existem algumas condições nas quais qualquer um poderá eximir-se da obrigação de depor, segundo o CPP. Uma delas quando a testemunha é ascendente ou descendente do acusado, "salvo quando não for possível, por outro modo, obter-se ou integrar-se a prova do fato e de suas circunstâncias" (art. 206). Considerando-se que boa parte dos episódios de violência sexual contra crianças ocorre no âmbito doméstico (Ramalho, 2012), tendo por destaque pais e padrastos (Waiselfisz, 2012), nota-se que o CPP lista algumas circunstâncias nas quais haveria argumentos para que a testemunha pudesse tentar eximir-se desse papel. Sobre a prevalência de tipos de violência entre crianças e adolescentes, observa-se que aqueles relativos à negligência/abandono e física possuem maior prevalência nos levantamentos realizados (Krug, 2002; Ramalho, 2012).

A criança e o adolescente no depoimento especial encerram em si, potencialmente, duas faces, a de vítima e a de testemunha. Ao mesmo tempo, vimos que, no que tange aos menores de 14 anos, conforme o CPP, não repousaria sobre o discurso dessas personagens o compromisso de que a verdade a ser assimilada pelo aparato judicial fosse dita. Nesse cenário, de que modo a memória seria expressa? O que seria uma memória que não tem um referente necessário, a verdade, e que, ao mesmo tempo, pode buscar um destinatário para expressar-se?

\section{O testemunho entre a memória e a necessidade de falar}

O contexto apresentado até aqui nos oferece oportunidade para analisarmos, ainda que brevemente, as relações entre testemunho e memória e seus possíveis desdobramentos na tomada de depoimento.

Para tanto, devemos ter em perspectiva que Agamben (2008) nos esclarece de que há em latim três termos para definir o testemunho: (i) testis, que "indica a testemunha enquanto intervém como terceiro na disputa entre dois sujeitos" (p. 150); (ii) superstes, que "é quem viveu até o fundo uma experiência, sobreviveu à mesma e pode, portanto, referi-la aos outros" (p. 150); e (iii) auctor, que "indica a testemunha enquanto o seu testemunho pressupõe sempre algo - fato, coisa ou palavra - que lhe preexiste, e cuja realidade e força devem ser convalidadas ou certificadas" (p. 150). Logo, observa-se que a testemunha no depoimento especial teria uma relação estreita com superstes, conforme a classificação indicada por Agamben. Como vimos, a criança (ou o adolescente) no depoimento especial seria a um só tempo "vítima e testemunha", isto é, "quem viveu até o fundo uma experiência, sobreviveu à mesma e pode, portanto, referi-la aos outros", como vimos acima.

Nessa perspectiva, a gravação em mídia do testemunho da criança/adolescente seria o clímax do procedimento de depoimento especial? Seria esse arquivo o télos do recolhimento das palavras da criança (ou do adolescente), aquilo que garantiria a veracidade do passado ou a pouparia do sofrimento? Sobre isso, Seligmann-Silva (2009) aponta-nos que "O trabalho da memória procede [...] a partir de nosso presente em direção ao passado" (p. 2). 
Se a

hipervalorização

do testemunho

já foi objeto

de crítica

(Sarlo, 2007),

Seligmann-Silva

(2003) apresenta-

nos uma de suas

características

principais, qual

seja, a de portar

em si algo

da ordem do

irrepresentável.
Assim, o testemunho não é simplesmente o que recupera o passado, mas também o que, em alguma medida, o estabelece, tentativa de constituir sentido quando muitas vezes isso não seria possível.

Anunciar a questão desse modo permite relançar pontos de orientação para nossa análise que não se pautem, exclusivamente, na discussão sobre a qualidade da lembrança, eficácia dos processos de rememoração ou falsas memórias (Stein, 2010). Todas essas perspectivas são importantes e, de uma maneira ou de outra, ligadas à história da Psicologia jurídica, isto é, à interface entre o sistema judicial e as práticas psi. Todavia, o campo de discussão desse tema permite-nos também partir de outras referências.

Essas referências podem pautar-se na imensa trilha aberta pelo lugar do testemunho no Século XX. Em parte, esse lugar é constituído pelas narrativas de sobreviventes da Shoah, não se restringindo a isso, contudo (Seligmann-Silva, 2003). Não seria possível a apropriação da multiplicidade de estudos desse campo para a análise do tema que abordamos aqui? Ali, estão em jogo a sobrevivência a uma situação-limite e a expressão da memória com base em uma narrativa, tais como apresentadas por Primo Levi, Jorge Semprún e tantos outros. Esse testemunho conjuga a uma só vez o dever de falar, a informação sobre o passado e a certeza de que algo nessa transmissão ocorre de modo incompleto, falta de representação para o horror vivido.

Se a hipervalorização do testemunho já foi objeto de crítica (Sarlo, 2007), SeligmannSilva (2003) apresenta-nos uma de suas características principais, qual seja, a de portar em si algo da ordem do irrepresentável. Ainda segundo Seligmann-Silva, o testemunho possui outra dupla característica, não só forma de esquecimento, mas também libertação da cena traumática. Fala-se para esquecer, não só para lembrar.
É possível ler em Agamben os mesmos traços salientados por Seligmann-Silva acerca do testemunho, mas com outra ênfase. Nele, encontramos as seguintes afirmações: "o testemunho traz uma lacuna" (Agamben, 2008, p. 42) ou "o testemunho vale essencialmente por aquilo que nele falta" (Agamben, 2008, p. 43). Todavia, Agamben acentua em seu estudo o que poderia ser entendido como uma aporia do testemunho: "no testemunho, há algo similar a uma impossibilidade de testemunhar" (Agamben, 2008, p. 43). Ou seja, algo no testemunho resistiria a ser narrado, como se um resto perdurasse, sempre, um pouco além ou aquém do dito, revelando a impossibilidade de uma narrativa exaustiva ou completa. Ao discurso da testemunha, nos casos analisados por Agamben e Seligmann-Silva, faltaria a representação que pudesse assinalar a transmissão integral da experiência vivida. O que esse discurso nos revela é, por fim, a lacuna que essa falta expressa, o resíduo que encontrou as vias da comunicação.

O resto, no contexto que estamos tratando aqui, deve ser entendido de várias formas, sobretudo quanto aos modos como o testemunho pode ocorrer. Isto é, desde a hesitação até a recusa, passando pelos enganos e tropeços da memória, tudo que se constitua como índice de uma assimetria entre presente e passado, entre o presente e aquilo que se quer recuperar, ou esquecer, o obstáculo à certeza da coincidência entre o evento passado e o momento de sua atualização no discurso.

Nessa relação com as palavras, devemos lembrar que um dos modos de nomear o intermediário nos procedimentos de tomada de depoimento especial é o de "intérprete", embora não seja a único (Childhood, 2011). O que significaria acreditar que um intérprete é necessário junto à criança ou ao adolescente? Isso seria o reconhecimento de que algo na palavra da testemunha 
insistiria em não ser traduzido para a cena jurídica, sendo mesmo marca de uma impossibilidade? O intérprete seria aquele que atestaria esse limite? Não existe um consenso sobre as respostas possíveis a essa pergunta. Todavia, é relativamente claro do que vimos até aqui que algumas práticas ancoram o procedimento no papel de intermediário, tornando-o central; outras, não o utilizam. E, entre essas duas posições, há uma terceira alternativa em que se observa o intermediário como uma possibilidade do procedimento, secundária frente a outros itens que o compõem (Childhood, 2011; Conselho Econômico e Social, 2005; Jonker \& Swanzen, 2007; Ministry of Justice, 2011; United Nations Office on Drugs and Crime, 2009).

No testemunho do sobrevivente, pressupõese a necessidade de falar, a qual não se impõe a todos do mesmo modo ou no mesmo tempo. No testemunho judicial, em particular daquele que abordamos neste trabalho, em princípio, trata-se de perspectiva um pouco diferente. É o sistema de justiça que demanda que algo seja dito. Nesse contexto, como ouvir a vítima? Como ouvir sua vontade ou sua recusa de falar? E o que fazer com isso? Como apresentá-la a um sistema que estaria lá para protegê-la, mas pode não saber fazêlo (ou não ter os meios para tanto)? Como equilibrar proteção e responsabilização?

Uma resposta a essas indagações, no Canadá, traduz-se no fato de que a preparação da criança para a audiência é uma etapa importante do procedimento. Esse trabalho requer um tipo de atenção que se desenrola por um período delimitado, desdobrando-se em certo número de encontros (Cunningham \& Hurley, 2007; 2007a). Esse acolhimento está previsto também nas diretrizes internacionais e colaboraria para que o testemunho viesse a encontrar sua melhor via de expressão, se possível (United Nations Office on Drugs and Crime, 2009).
Sobre a relação entre as demandas dirigidas ao aparato judicial no Canadá e o tratamento dado pelo sistema judicial a elas, Cunningham (2011a) assinala que:

sabemos que em nossa jurisdição surgem mais de 500 casos criminais por ano, que envolvem a necessidade de crianças [...] prestarem o depoimento. Embora a maioria desses casos seja encaminhada ao Fórum, avalia-se não haver necessidade de a criança prestar o depoimento, geralmente em decorrência de o réu [...] confessar a culpa. Cerca de 200 casos por ano são encaminhados para o nosso Centro para preparar e auxiliar a criança a prestar o depoimento [...] o número final de crianças com que trabalhamos por ano é de 150 crianças. Além disso, embora preparemos 150 crianças, na 'hora $\mathrm{H}^{\prime}$ o réu pode assumir a culpa e acabamos, geralmente, encaminhando ao Fórum apenas 100 crianças - crianças que efetivamente precisam dar o seu depoimento (p. 163, grifo nosso)

Importante notar que, conforme a citação acima, o procedimento citado efetivamente recebe, em média, menos de $40 \%$ dos casos de suspeita de violência sexual que potencialmente levariam ao depoimento de crianças. E do universo total, apenas 20\% de crianças efetivamente depõem. Quais são os mecanismos que levam de modo tão recorrente à confissão do réu, nessa citação? Que variáveis poderiam contribuir para que a necessidade do depoimento de crianças fosse a exceção, tal como se depreende da citação acima? O que significaria para o sistema judicial e para os serviços envolvidos mais diretamente no procedimento de depoimento especial, a pretensão de abarcar integralmente as demandas recebidas? No contexto dessa citação, seria possível acreditar que o depoimento da criança sempre deva ocorrer? Quatro perguntas que restam aqui como diretrizes para futuros trabalhos, mas cujas respostas podem marcar, desde já, o equilíbrio necessário entre proteção e responsabilização. 


\section{Considerações finais}

Ao longo deste trabalho, percorremos alguns pontos em torno da proposta de depoimento especial de crianças e adolescentes, bem como dos pressupostos dessa prática tanto no Brasil quanto no exterior. Para isso, analisamos o procedimento tal como feito no Canadá e destacamos algumas diretrizes das práticas realizadas aqui.

Em um segundo momento, apresentamos breves considerações sobre o tema do testemunho e da memória, com base nos argumentos de Agamben e Seligmann-Silva, com o intuito de apontar que o testemunho judicial pode ser analisado sob a perspectiva de outras ferramentas conceituais que não aquelas usuais para esse campo. Ao mesmo tempo, verificamos como no Canadá o testemunho da criança impõe-se como um último recurso, abarcando um universo reduzido de casos em comparação ao número total daqueles apresentados à cena judicial.

Reconheceu-se que o testemunho tem os seus limites, e que, portanto, a integralidade do evento pode não ser recuperável tal como o aparato judicial pressuporia necessário. Nesse cenário, ao lado do intermediário encontramos a "pessoa de confiança" e os serviços de atenção à testemunha (ou de proteção à vítima) e, com eles, é o lugar e a função da justiça que se encontrariam redimensionados: proteção e responsabilização seriam dois lados inseparáveis de uma mesma moeda.

Tratar do depoimento da criança a partir de uma perspectiva sistêmica, no qual proteção e responsabilização são dois eixos necessários, é uma exigência dirigida a todos, inclusive aos que se inserem na interface entre a Psicologia e o sistema judicial. Estabelecer e precisar a relação entre os lugares a serem ocupados nesse cenário é o desafio que se apresenta a nós neste momento e para os quais precisamos estar atentos. De outro modo, permaneceremos cristalizados em duas posições: a de que fazer falar e registrar é tudo resolver ou a de que não há nada a fazer porque tudo é precipitar a criança em dano maior.

As perguntas sobre quem deve ser protegido (e como), bem como sobre os direitos a serem assegurados, estão sendo respondidas no Brasil pelas experiências em curso. Contudo, alguns passos a mais se mostram necessários. Que no testemunho algo resista a ser arquivado, talvez seja uma consideração que permita fazer avançar a circulação da palavra entre posições que acreditam saber qual é o melhor interesse da criança. É porque nem tudo pode ser dito no testemunho, que a atenção à criança e ao adolescente pode expressar-se de vários modos, mesmo no sistema judicial, como a experiência canadense permite ver com tanta clareza. 


\section{José César Coimbra}

Doutor em Memória Social pela Universidade Federal do Estado do Rio de Janeiro. Psicólogo no Tribunal de Justiça do Estado do Rio de Janeiro, Rio de Janeiro - RJ - Brasil.

E-mail: arcoim@yahoo.com.br

Endereço para envio de correspondência:

Praia do Flamengo, 314/5. CEP: 22210-030. Rio de Janeiro, RJ.

Recebido 11/11/2012, 1a Reformulação 07/11/2013, Aprovado 12/12/2013.

\section{Referências}

Agamben, G. (2008). O que resta de Auschwitz o arquivo e a testemunha: homo sacer III. São Paulo: Boitempo.

Alvarez, L. (2012). La escucha de los niños víctimas y los dispositivos psi jurídicos (entre el Pantéon y la Prefectura de Policía). In Leila M.T. de Brito (org.), Escuta de Crianças e de Adolescentes: reflexões sentidos e práticas (pp. 31-50). Rio de Janeiro: EdUerj.

Brito, L. (2012). Das avaliações técnicas aos depoimentos infanto-juvenis: novos rumos dos casos de suspeita de abuso sexual. In Leila M.T. de Brito (org.), Escuta de Crianças e de Adolescentes: reflexões sentidos e práticas (pp. 51-86). Rio de Janeiro: EdUerj.

Brito, L. \& Parente, D. (2012). Inquirição judicial de crianças: pontos e contrapontos. Psicol. Soc., Belo Horizonte, 24(1), 178-186. Recuperado de http:// www.scielo.br/scielo.php?script=sci_arttext\&pid=S0102$71822012000100020 \& \operatorname{lng}=\mathrm{en}^{\&} \mathrm{nrm}={ }^{-}$iso

Childhood. (2011). I Encontro Nacional de Experiências de Tomada de Depoimento Especial de Crianças e Adolescentes no Judiciário Brasileiro - Recomendações. Brasília, DF: Autor. Recuperado de http://www.childhood.org.br/I_encontro_ nacional/Recomendacoes-I-Encontro-Exp-DepoimentoEspecial-Judiciario-Final[1].pdf

Coimbra, J. (2001). Resumo do curso 'Enfrentamento do abuso sexual na criança e adolescente', de Tilman Fürniss, Centro Educacional S. Camilo. Recuperado de Scribd: http://www. scribd.com/doc/36780533/Tilman-Furniss-Resumo-deCurso-BH-2001

Conselho Federal de Psicologia (2010). Resolução n. 10. Institui a regulamentação da Escuta Psicológica de Crianças e Adolescentes envolvidos em situação de violência, na Rede de Proteção. Recuperado de Psicologia On Line - Conselho Federal de Psicologia: http://bit.ly/Lo6SOF

Conselho Nacional de Justiça (2010). Recomendação n. 33, de 23 de novembro de 2010. Recomenda aos tribunais a criação de serviços especializados para escuta de crianças e adolescentes vítimas ou testemunhas de violência nos processos judiciais. Depoimento Especial. Recuperado de Conselho Nacional de Justiça: www.cnj.jus.br/atos-administrativos/atos-dapresidencia/322-recomendacoes-do-conselho/12114recomendacao-no-33

Conselho Nacional do Ministério Público. (2012). CNMP, Relatório nacional da execução da meta 2: um diagnóstico da investigação de homicídios no país. Brasília, DF: Autor. Recuperado de: http://www.cnmp.gov.br/portal/images/ stories/Enasp/relatorio_enasp_FINAL.pdf
Convenção sobre os direitos da criança. (1989). Adotada em Assembleia Geral das Nações Unidas em 20 de novembro de 1989. Recuperado de Unicef: http://www.unicef.org/brazil/pt/ resources_10120.htm

Court \& Tribunal Services. (2013). Child Witness Service. Recuperado de Government of Western Australia Department of General Attorney: http://www.courts.dotag. wa.gov.au/C/child_witness_service.aspx

Cunningham, A. (2011). A escuta de crianças abusadas sexualmente para compreensão do processo de revelação. In L. C. A. Williams \& E. A. C. Araújo (org.), Prevenção do Abuso Sexual Infantil: um enfoque interdisciplinar (pp. 84-97). Curitiba, PR: Juruá.

Cunningham, A. (2011a). Dificuldades apresentadas por crianças ao prestar depoimento no fórum judicial e como ajudá-las. In L. C. A. Williams \& E. A. C. Araújo (org.), Prevenção do Abuso Sexual Infantil: um enfoque interdisciplinar (pp. 162-172). Curitiba, PR: Juruá

Cunningham, A. \& Hurley, P. (2007). Hearsay evidence and children. Recuperado do Centre for children and families in the justice system: http://www.Ifcc.on.ca/6 HearsayEvidence. pdf

Cunningham, A. \& Hurley, P. (2007a). Testimony outside the courtroom. Recuperado de Centre for children and families in the justice system: http://www.Ifcc.on.ca/2_ OutsideCourtroom.pdf

Cunningham, A. \& Hurley, P. (2007b). Designated Support Person. Recuperado de Centre for children and families in the justice system: http://www.Ifcc.on.ca/5_SupportPerson.pdf

Cunningham, A. \& Stevens, L. (2011). Helping a child be a witness in court. Recuperado de Centre for children and families in the justice system: http://www.Ifcc.on.ca/Helping_a_Child Witness.pdf

D'Agostino, R. (2012). País tem poucas salas especiais para ouvir crianças vítimas de estupro. Recuperado de G1: http:// g1.globo.com/brasil/noticia/2012/05/pais-tem-poucas-salasespeciais-para-ouvir-criancas-vitimas-de-estupro.html

Davies, G., Westcott, H. (1999). Research Series - Paper 115. Interviewing Child Witness under the Memorandum of Good Practice: A reserach review. London: RDS. Recuperado de RDS: http://217.35.77.12/research/england/justice/fprs115. pdf

Decreto-Lei n. 3.689, de 3 de outubro 1941. (1941). Código de Processo Penal. Recuperado de Presidência da República - 
Casa Civil: http://www.planalto.gov.br/ccivil 03/decreto-lei/ del3689.htm

Fürniss, T. (1993). Abuso sexual da criança: uma abordagem multidisciplinar. Porto Alegre: ArtMed.

lucksch, M. (2012). Depoimento especial da criança e do adolescente: como definir um lugar diferenciado para a oitiva e para a escuta. In Violência sexual e escuta judicial de crianças e adolescentes: a proteção de direitos segundo especialistas. São Paulo: Associação dos Assistentes Sociais e Psicólogos do Tribunal de Justiça do Estado de São Paulo. Recuperado de AASPTJ-SP: http://www.aasptjsp.org.br/ noticia/livro-escuta-de-crian $\%$ C3\%A7as-e-de-adolescentesprote $\% \mathrm{C} 3 \% \mathrm{~A} 7 \% \mathrm{C} 3 \% \mathrm{~A} 3 \mathrm{O}-$ de-direitos-segundo-especialistas

Jonker, G., Swanzen, R. (2007). Serviços de intermediação para crianças-testemunhas que depõem em tribunais criminais na África do Sul. SUR Revista Internacional de Direitos Humanos, 4(6), 93-119. doi.org/10.1590/S1806-64452007000100006

Justice Education Society. (2012). Testifying in court. Recuperado de http://www.courtchoices.ca/

Krug, E. (2002). Relatório mundial sobre violência e saúde. Genebra: Organização Mundial da Saúde.

Lei n. 8.069, de 13 de julho de 1990. (1990). Dispõe sobre o Estatuto da Criança e do Adolescente e dá outras providências. Recuperado de Presidência da República - Casa Civil: http://www.planalto.gov.br/ccivil_03/leis//8069.htm

Ministério Público do Estado do Rio de Janeiro. (2012). MPRJ realiza encontro internacional para debater a necessidade das salas de escuta para colheita de depoimento especial de crianças e adolescentes. Recuperado de MPRJ: http:// www.mp.rj.gov.br/portal/page/portal/Internet/Imprensa/ Em_Destaque/Noticia?caid $=293$ \&iditem $=21497364$

Ministry of Justice (2011). Vulnerable and Intimidate Witness - A Police Service Guide. London: Ministry of Justice. Recuperado de Ministry of Justice: http://bit.ly/1eaNcQa

Motzkau, Johanna (2005). Cross-examining suggestibility: memory, childhood, expertise - children's testimony between psychological research and juridical practice. In Czerederecka, A.; Jaskiewicz-Obydzinska, T.; Roesch, R. and Wojcikiewicz, J. (Eds), Forensic psychology and law: facing the challenges of a changing world. (pp. 201-212). Crakow, Poland: Krakow: Institute of Forensic Research Publishers. Recuperado de Open Research Online: http:// oro.open.ac.uk/7234/1/pdf.pdf

Nascimento, A. (2012). Depoimento sem dano: considerações jurídico-processuais. In Leila M.T. de Brito (org.), Escuta de Crianças e de Adolescentes: reflexões sentidos e práticas (pp. 11-30). Rio de Janeiro: EdUerj.

New Zealand's Criminal Justice System. (2012). Questioning of child witnesses. Recuperado de Ministry of Justice: http:// www.justice.govt.nz/publications/global-publications/a/ alternative-pre-trial-and-trial-processes-for-child-witnessesin-new-zealands-criminal-justice-system/questioning-ofchild-witnesses

Northcott, M. (2011). Facilitating testimony for child victms and witnesses. Victms of Crime Research Digest, n.2, p. 17-23. Recuperado de Department of Justice - CA:http://www. justice.gc.ca/eng/pi/rs/rep-rap/rd-rr/rd09_2-rr09_2/p3.html
PL n.4126. (2004). Acrescenta o art. 161-A ao Decreto Lei n.3689, de 3 de outubro de 1941 - Código de Processo Penal, para prever regras especiais quanto à realização de laudo pericial e psicossocial nos crimes contra a liberdade sexual de criança ou adolescente. Recuperado de Presidência da República - Casa Civil: http://imagem.camara.gov.br/Mostralntegralmagem. asp? strSiglaProp $=$ PL\&intProp $=4126 \&$ intAnoProp $=2004 \&$ intParteProp $=1$

Ramalho, S. (2012, maio 23). Abuso sexual: 14 crianças vitimadas por dia - Ministério da Saúde revela que mais de 5 mil menores de dez anos foram violentados em 2011. O Globo, p. 13.

Ramos, S. (2010). A atuação do Sistema de Garantia de Direitos em casos de violência sexual contra criança: Uma análise processual. Dissertação de Mestrado, Instituto de Psicologia, Universidade do Estado do Rio de Janeiro, Rio de Janeiro.

Resolução Conanda 113. (2006). Resolve aprovar os seguintes parâmetros para a institucionalização e fortalecimento do Sistema de Garanta dos Direitos da Criança e do Adolescente. Recuperado de Pró-Menino: http://www.promenino.org. br/Ferramentas/Conteudo/tabid/77/Conteudold/e48c914ed215-405c-82d8-75096336d0ec/Default.aspx

Santos, B. \& Gonçalves, I. (2008). Depoimento sem medo. Recuperado de Childhood Brasil: http://www.childhood. org.br/wp-content/uploads/2008/11/DEPOIMENTO-SEMMEDO.pdf

Sarlo, B. (2007). Tempo passado: cultura da memória e guinada subjetiva. Belo Horizonte: UFMG

Schulz, B. (2012). Ficção completa. São Paulo: Cosac Naify.

Seligmann-Silva, M. (2003). Reflexões sobre a memória, a história e o esquecimento. In Márcio Seligmann-Silva (org.), História, memória, literatura: o testemunho na era das catástrofes (pp. 59-88). Campinas, SP: Ed.Unicamp.

Seligmann-Silva, M. (2009). De Flusser a Benjamin: do pósaurático às imagens técnicas. Flusser Studies: Multilingual Journal for Cultural and Media Theory, 8, 1-17. Recuperado de http://www.flusserstudies.net/sites/www.flusserstudies. net/files/media/attachments/seligmann-flusser-benjamin.pdf

Senado Federal (2008). Resumo de audiência. Referente à Audiência Pública realizada no Senado Federal no dia 1o de julho de 2008, sobre o procedimento relativo à inquirição judicial de crianças e adolescentes, para instruir o Projeto de Lei da Câmara no 35, de 2007.

Stein, L. (2010). Falsas memórias: fundamentos científicos e suas aplicações clínicas e jurídicas. Porto Alegre: ArtMed.

United Nations Economic and Social Council. (2005). ECOSOC: Guidelines on justice in matters involving child victims and witnesses of crime - Resolution 2005/20. Recuperado de: http://www.un.org/en/pseataskforce/docs/guidelines_on_ justice in matters involving_child victims_and.pdf $>$.

United Nations Office on Drugs and Crime. (2009). UNODC, Justice in matters involving child victms and witnesses of crimeModel law and related commentary. Recuperado de UNODC: http://www.unodc.org/documents/justice-and-prison-reform/ Justice_in_matters...pdf

Waiselfisz, J. J. (2012). Mapa da Violência - Crianças e Adolescentes do Brasil. Rio de Janeiro: Cebela/Flacso. Recuperado de Mapa da Violência: http://www.mapadaviolencia.org.br/pdf2012/ MapaViolencia2012_Criancas_e_Adolescentes.pdf 